\title{
Transplantation of organs from donors with Hepatitis C: the potential to substantially increase transplant activity
}

\author{
PB Trotter, M Robb, DM Summers, I Ushiro-Lumb, J Powell, JA Bradley , CJE Watson, J Neuberger
}

1. NHS Blood and Transplant 2. University of Cambridge, Department of Surgery 3. Transplant Unit, Edinburgh Royal Infirmary

\section{Introduction}

With the introduction of direct acting antivirals (DAA) Hepatitis $\mathrm{C}$ virus (HCV) is now a potentially curable condition. HCV positive (HCV+ve) donors therefore represent a valuable and unutilised resource of potentially transplantable organs.

\section{Aims}

1) To determine the number of $\mathrm{HCV}+\mathrm{ve}$ deceased donors in the UK and establish how their organs were used

2) To establish the quality of discarded HCV+ve donor organs

3) Estimate the benefit of using $\mathrm{HCV}+\mathrm{ve}$ organs for all organ transplantation

\section{Methods}

- UK Transplant Registry

- 1st January 2000- 31st Decemeber 2015

- Identify all HCV antibody positive consented donors, identify all recipients of $\mathrm{HCV}+\mathrm{ve}$ donor organs Establish quality of discarded $\mathrm{HCV}+\mathrm{ve}$ donors using eGFR, liver function tests and donor risk indices

- Retrospective matching to patients who died whilst awaiting an organ transplant (Kidney, Liver, Heart and Lung)

- Cost analysis using current cost of combination sofosbuvir + ledipasvir, renal transplantation and haemodialysis

\section{Results}

- Over the 16-year study period there were $246 \mathrm{HCV}+\mathrm{ve}$ donors identified

- Only $76(31 \%)$ proceeded to organ donation resulting in 63 liver, 27 kidney and 2 heart transplants (figure 1)

- The presence of HCV in the donor did not adversely impact transplant outcomes (figure 2)
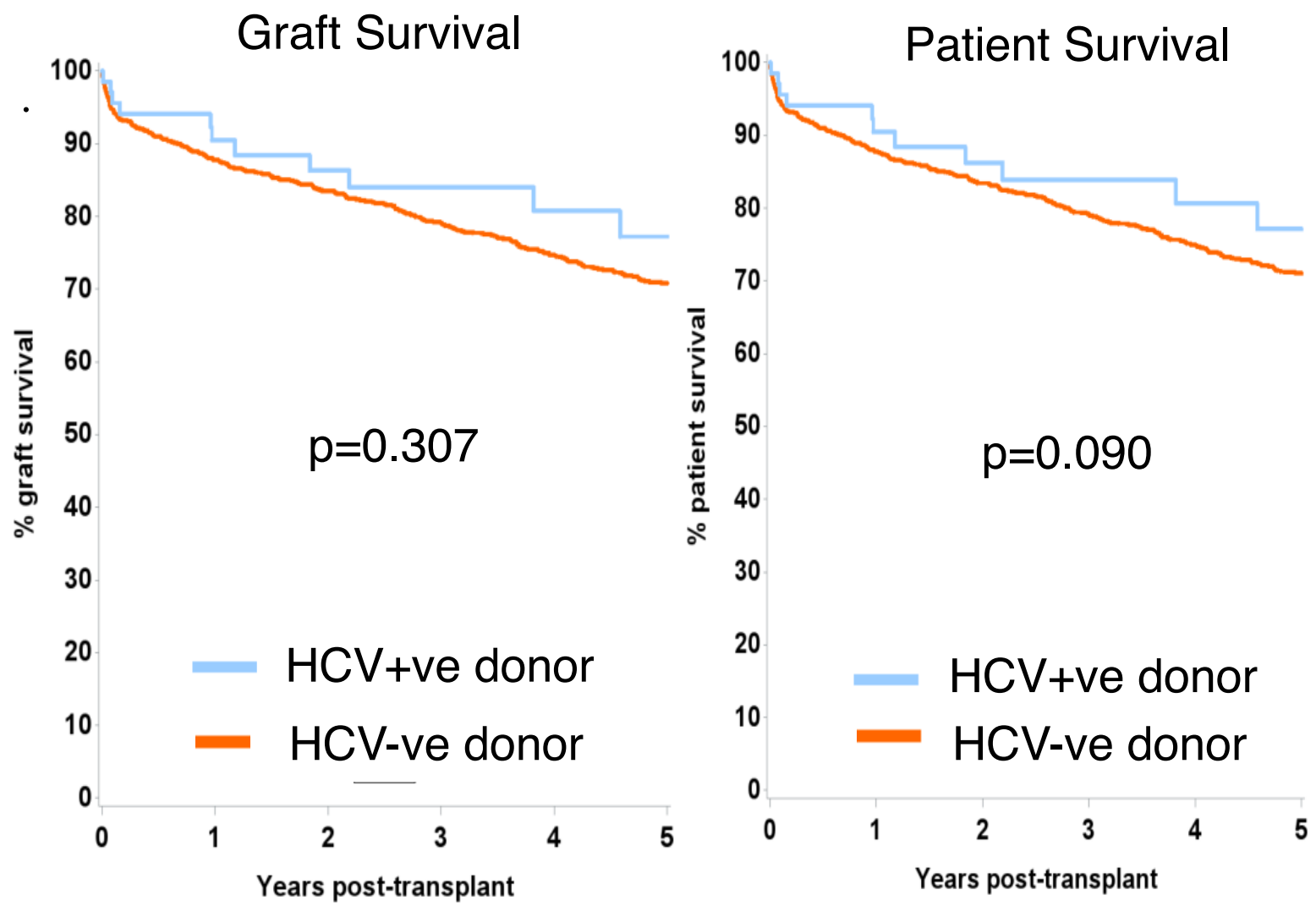

Figure 2. Unadjusted 5 year liver patient survival and death censored graft survival by whether or not the recipient received a HCV+ve liver

\begin{tabular}{|l|l|}
\hline \multicolumn{1}{|c|}{ Kidney } & \multicolumn{1}{|c|}{ Liver } \\
\hline eGFR 103 $(71-144.5) \mathrm{ml} / \mathrm{min}$ & Bilirubin $(\mu \mathrm{mol} / \mathrm{ml}) 13(8-22)$ \\
Creatinine $(\mu \mathrm{mol} / \mathrm{l}) 68(51-101)$ & $\begin{array}{l}\text { ALT }(\mathrm{IU} / \mathrm{l}) 53(29-111) \\
\text { Alk Phos }(\mathrm{IU} / \mathrm{l}) 93(70-133)\end{array}$ \\
\hline UKKDRI 50\% best two quartiles & DLI 28.7\% best two quartiles \\
\hline
\end{tabular}

Table 1. Estimation of quality of livers and kidneys from non-proceeding $\mathrm{HCV}+\mathrm{ve}$ potential donors

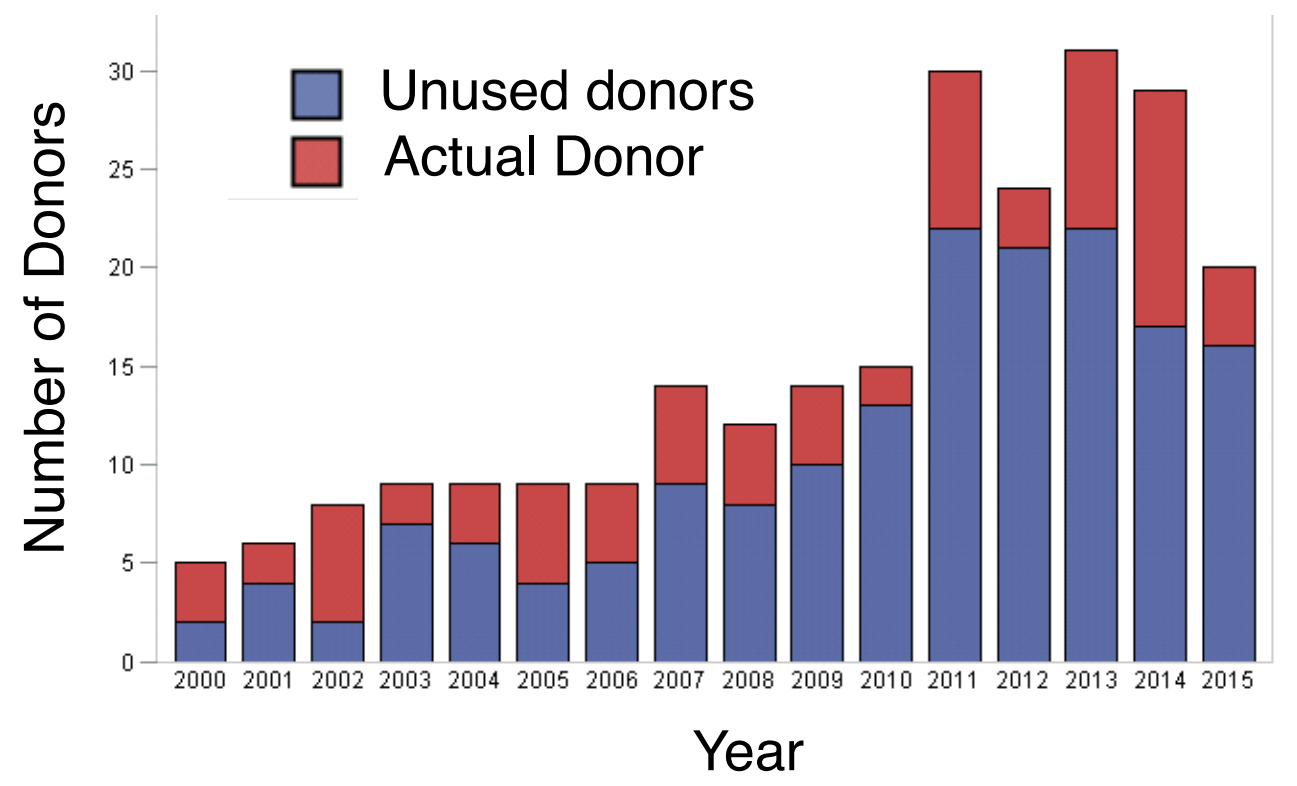

Figure 1. Total number of Hepatitis $C$ positive donors whose organs were used and not used for transplantation

Poor Function

Family Refusal

DCD

Past History

Virology
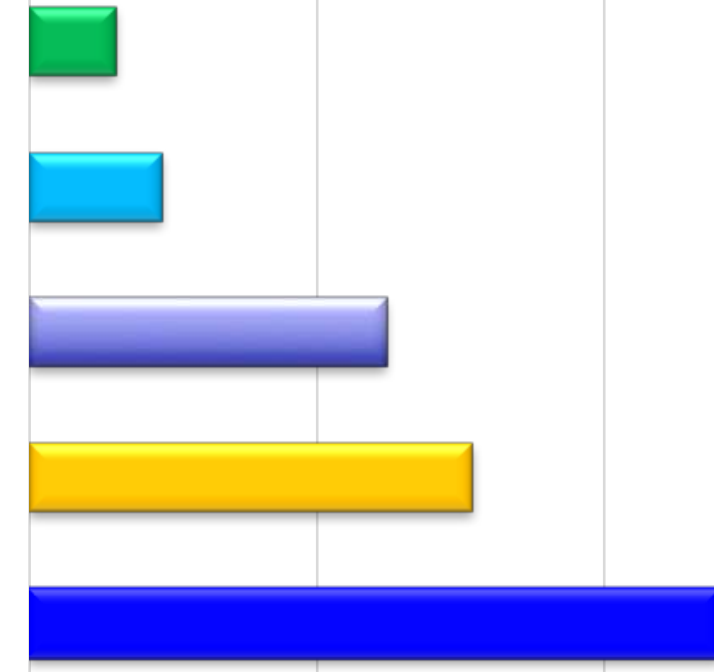

0

50

100

150

Figure 3. Reasons for $\mathrm{HCV}+\mathrm{ve}$ donors to be declined for transplant

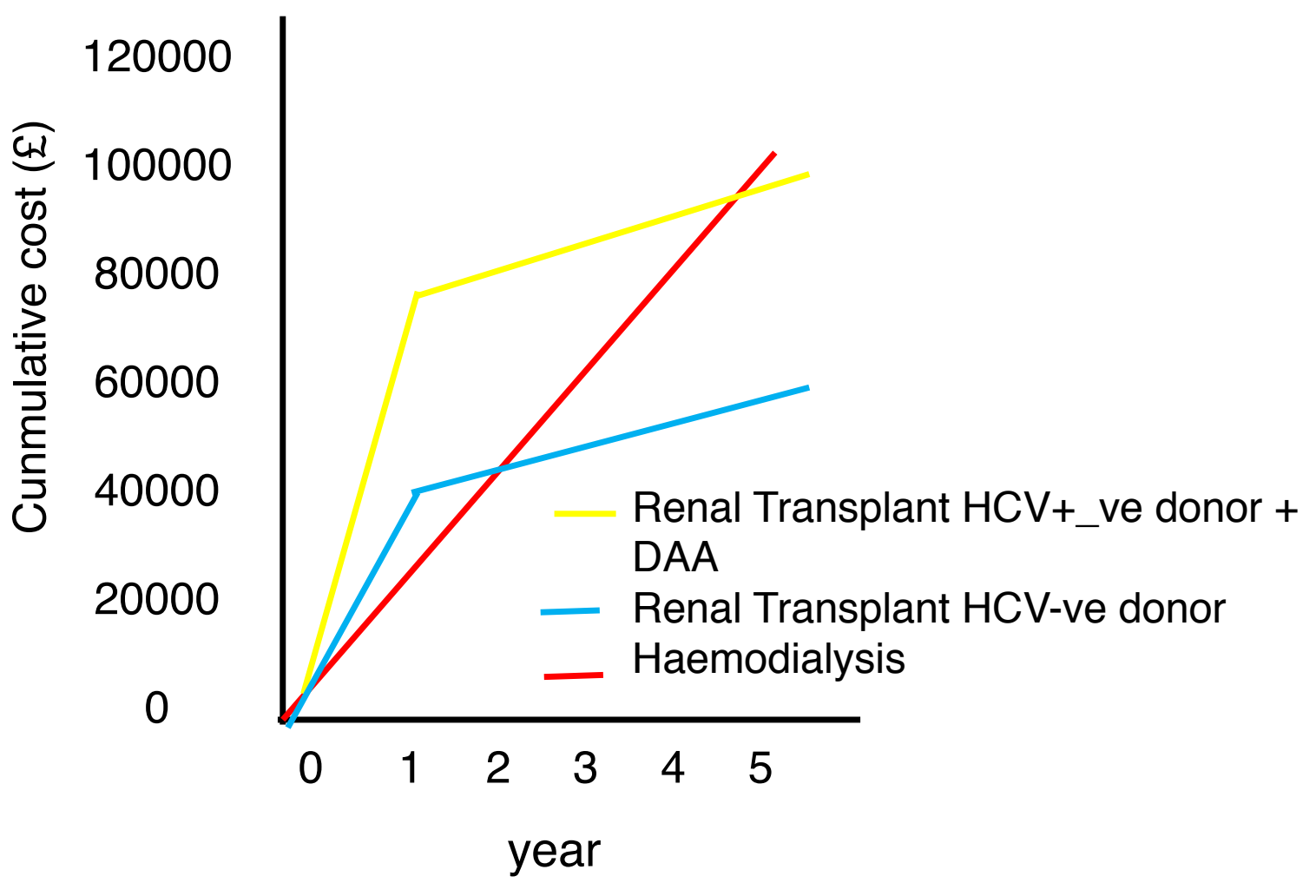

- Transplanting a HCV+ve kidney and treating with combination DAA was cost neutral with dialysis at 5 years

- Retrospective matching to patients who died on the list identified 1489 missed opportunities for transplantation

\section{Interpretation}

- Large number of HCV+ve donors declined

- Good Quality donors apart from the presence of HCV

- Potential to substantially increase the organ donor pool and improve the quality and duration of live for people on the waiting list

- Use of HCV+ve kidneys would be cost effective compared to dialysis 